\title{
USGS Laboratory Review Program Ensures Analytical Quality
}

\section{Laboratories Provide Data for USGS Projects}

The U.S. Geological Survey (USGS) investigates the occurrence, quantity, quality, distribution, uses, and movement of the surface and ground waters of the Nation. Studies involving water quality are designed to measure the current quality of our Nation's water and changes that are occurring with time and environmental control efforts. As a result, these investigations are highly dependent upon the integrity of the data produced by the laboratories that analyze environmental samples collected during a study.

Although most analyses are performed by the USGS National Water Quality

Laboratory in Arvada, Colorado, there are approximately 65 other laboratories that also provide analytical data to USGS projects. To ensure that data from these laboratories are comparable and of satisfactory quality, the Branch of Technical Development and Quality Systems (BTD\&QS) implemented a laboratory review process that evaluates their technical and quality-assurance programs. This review program has been in operation since 1987. During this period, approximately 16 laboratory reviews per year have been performed.

\section{Laboratory Review Process}

The review process consists of four steps: (1) a preliminary survey, (2) an onsite review, (3) a debriefing, and (4) a written report. The preliminary survey includes a compilation of the type and number of determinations performed for USGS projects, an evaluation of the laboratory's quality-assurance (QA) plan for completeness and scientific integrity, and a review of results from interlaboratory evaluation programs. The onsite review involves an examination of the following major items in the laboratory.
- Sample-management system

- Qualifications and responsibilities of major personnel

- Space and other physical resources

- Conformance of laboratory operations to quality-assurance/quality-control plan

- Analytical methods used

- Standard operating procedures of the laboratory

- Records including analysts' notebooks, quality-control charts, and instrument-maintenance notebooks

- Types and numbers of instruments available

- Use of reference materials and other quality-assurance samples in the laboratory

- Quality-control checks used to verify adequacy of completed analysis

- Data-entry and data-review procedures

- External-evaluation programs in which the laboratory participates and results from these programs

- Safety and training procedures

The debriefing, which is conducted after the completion of the onsite review, gives laboratory personnel an opportunity to provide further input and to correct any misconceptions that the review team may have obtained. The major findings with regard to the strengths and weaknesses of the laboratory's QA program are discussed. The written report documents the review findings and requests a response from the laboratory that will describe corrective actions implemented as a result of the onsite review.
The review team usually consists of three individuals. Two have a background in analytical chemistry and are, therefore, knowledgeable about the approaches that a laboratory should take when analyzing environmental samples; the third is either a member of the project team submitting the samples to the laboratory or a water-quality expert in the USGS District Office. The purpose of these reviews is twofold. The first is to improve the QA program of the laboratory, which will, in turn, improve the quality of data produced. The second is to ensure that the analytical data meet the needs of the environmental study. This is accomplished by encouraging laboratory and project personnel to address any problems or misunderstandings that may exist in the sampling or analytical parts of the study and that could, if not resolved, adversely affect the data quality.

Under this program, every laboratory will be reviewed on a 3-4 year cycle. The BTD\&QS will assist a laboratory in improving its performance if its QA program is found to be unsatisfactory; however, the laboratory will not be allowed to analyze samples for the USGS projects until the quality of analyses becomes satisfactory.

\section{Summary}

The USGS operates a review program for laboratories that analyze samples for USGS environmental investigations.

This program has been effective in providing QA feedback to laboratories while ensuring that analytical data are consistent, of satisfactory quality, and meet the data objectives of the investigation.

For additional information, contact the Branch of Technical Development and Quality Systems

U.S. Geological Survey

Box 25046, Mail Stop 401

Lakewood, CO 80225

—David E. Erdmann 
